\title{
The Etiology of Mastitis and its Impact on Lipid Peroxidation Product of Dairy Cows
}

\author{
Zigo František ${ }^{* 1}$, Vasil' Milan ${ }^{1}$, Silvia Ondrašovičová ${ }^{2}$ and Zigová Martina ${ }^{3}$ \\ ${ }^{1}$ Department of Animal Breeding, University of Veterinary Medicine and Pharmacy in Košice, Slovakia \\ ${ }^{2}$ Department of Anatomy, Histology and Physiology, University of Veterinary Medicine and Pharmacy in Košice, Slovakia \\ ${ }^{3}$ Department of Pharmacology, University of Pavol Jozef Šafárik in Košice, Faculty of Medicine, Slovakia \\ *Corresponding author: František Zigo, University of Veterinary Medicine and Pharmacy in Košice, Department of Animal Breeding, \\ Slovakia, Komenského 73, 04001 Slovakia
}

\begin{abstract}
ARTICLE INFO
Received: 梆 November 07, 2019

Published: 慧 November 14, 2019

Citation: Zigo František, Vasil' Milan, Silvia Ondrašovičová, Zigová Martina. The Etiology of Mastitis and its Impact on Lipid Peroxidation Product of Dairy Cows. Biomed J Sci \& Tech Res 22(5)-2019. BJSTR. MS.ID.003817.
\end{abstract}

Keywords: Mammary Gland; Mastitis; Diagnostic; Malonaldehyde; S. Aureus

\begin{abstract}
Background: On most farms the prevalence of mastitis and the number of infected cows is often unknown. These cases do not show any clinical signs and are identified only by California Mastitis Test (CMT) assessment and Somatic Cell Count (SCC) determination. One of the additional diagnostic methods of mastitis may be involve determination of lipid peroxidation end product in milk.
\end{abstract}

Objective: The aim of the study was to detect the main bacterial pathogens causing mastitis in dairy cows and their impact on lipid peroxidation product, using milk malondialdehyde (MDA) as an indicator of oxidative stress.

Methods: During the complex investigation of 123 lactating cows, 612 quarter milk samples were exanimated and classified by clinical examination, abnormal udder secretions, assessment of the CMT, with collecting of milk samples for detection of MDA and bacteriological identification of pathogens causing mastitis.

Results: Positive CMT score was recorded of 19.2\% (118) exanimated quarters and $12.5 \%$ (76) quarters were confirmed bacterial pathogens causing latent $1.3 \%$, subclinical (SM; 8.3\%) and clinical (CM; 3.0\%) mastitis. The most common bacterial isolates from the mastitis cases were staphylococci (67\%) included S. aureus, $S$. chromogenes, $S$. haemolyticus and $S$. warneri. The second most common cause of mastitis were $S$. uberis and $S$. faecalis. The concentrations of MDA were significantly higher from SM and CM cases than in milk samples from healthy cows. In addition, we found that quarter milk samples infected with $S$. uberis were higher MDA levels compared to other pathogens.

Conclusion: The higher MDA concentrations in SM and CM milk observed in this study showed that the oxidative stress of infected milk is higher than normal milk. In conclusion, the measurement of milk MDA level could be a potential biomarker for monitoring health status of the mammary gland.

\section{Introduction}

Worldwide, intramammary infection - mastitis is still one of the most important disease in the dairy sector. The disease is usually local but may become systemic, although rarely, in immunocompromised animals. The milk collected from cows with different type of inflammation, including mastitis, is characterized by an increased number of somatic cell count (SCC) and changes in milk composition which usually affects its processing properties [1]. It was proved that the antibacterial activity of polymorphonuclear cells generates reactive oxygen species (ROS). The accumulation of the ROS correlating with a chemical and physical changes in the milk and can lead to oxidative stress. Increase of oxidative stress in dairy cows because of high milk production can result in excess 
accumulation of ROS, which can induce lipid peroxidation and reduction of antioxidative activity [2].

One of the most reliable of lipid peroxidation product and widely used indexes of oxidative stress is MDA. Malondialdehyde is produced during the peroxidation of polyunsaturated fatty acids by the action of reactive oxygen species as a result of the depletion of antioxidant systems [3]. Oxidative stress in veterinary medicine and particularly in ruminant health is a relatively young field of research. Therefore, the goal of this study was to detect the etiology and occurrence of mastitis in dairy herd and their impact on lipid peroxidation product, using Milk Malondialdehyde.

\section{Materials and Methods}

\section{Herd and Udder Health Examination}

The practical part of the study was carried out in herd of 180 dairy cows of Slovak spotted cattle in west of the Slovakia. The cows were milked twice a day at 5:30 a.m. and 4:30 p.m. in the $2 \times 10$ fishing-milking parlour DeLaval 2x5 (Tumba, Sweden). To work were selected 153 lactating cows because 27 cows were separated in calving boxes. A complex examination of udder health status of each cow included clinical examination, examination fore-strip of milk, with CMT reaction, subsequent collecting of milk samples for SCC detection and bacteriological examination according to our previous study Zigo et al. [4].

\section{Experimental Groups Selection for MDA Determination}

Based on veterinary history, CMT assessment and clinical examination for measurement of milk MDA concentration were cows selected into three groups: control (healthy cows), cows with Subclinical (SM) and clinical (CM) mastitis. To a SM group were included 43 cows without clinical signs of mastitis or other illnesses but with positive CMT at least one quarter. Out of them were selected 77 quarters for MDA detection that showed a positive CMT (score 1-4). To a CM group were included seven cows with clinical signs and out of them were selected 15 quarters for MDA detection with high score of $\mathrm{CMT} \geq 3$. From all health cows with a negative score of CMT and without clinical sign was randomly selected seven animals (28 quarters) to the control group.

For MDA detection were normal and mastitic milk samples skimmed by centrifugation at $10,000 \mathrm{~g}$ for $20 \mathrm{~min}$ at $4^{\circ} \mathrm{C}$. Defatted milk was used for MDA concetration by spectrophotometric techniques. Malondialdehyde concentration was determined by the thiobarbituric acid method, which was modified from method of Andrei et al. [5].

\section{Statistical Analysis}

Data for milk MDA levels in selected groups of dairy cows were expressed as mean (M) \pm Standard Deviation (SD). Difference between groups were analysed by using Analysis of Variance (ANOVA) followed by Tukey-Kramer multiple comparison test and minimum criteria for statistical significance was set at $\mathrm{P} \leq 0.05$ for all. Approximate probabilities were evaluated with Post Hoc Test for the statistical analysis of MDA level between selected pathogens.

\section{Results and Discussion}

High-producing cows are highly susceptible to Intramammary Infection (IMI) due to Staphylococcus aureus or Streptococcus spp., and losses in milk yield are related to an increase in composite milk SCC. Sharma et al. [7] and Tenhagen et al. [8] reported that staphylococci were the predominant organisms isolated from mastitis milk samples followed by Streptococci, E. coli, Pseudomonas spp. and Klebsiella spp. The present findings are in accordance with the findings of our study. From 76 infected quarters (12.4\%) with positive bacteriological cultivation there was $10.5 \%, 65.8 \%$ and $24.0 \%$ classified as latent, subclinical and clinical mastitis, respectively.

After laboratory analyses,51 (67.1\%) were found positive for staphylococci, 8 (11.0\%) for streptococci and 7 (9.2\%) for E. coli with Pesudomonas spp. From staphylococci, CNS and CPS gave the highest percentages $47.4 \%$ and $19.7 \%$ representation on the aetiology of mastitis from the affected samples, respectively.

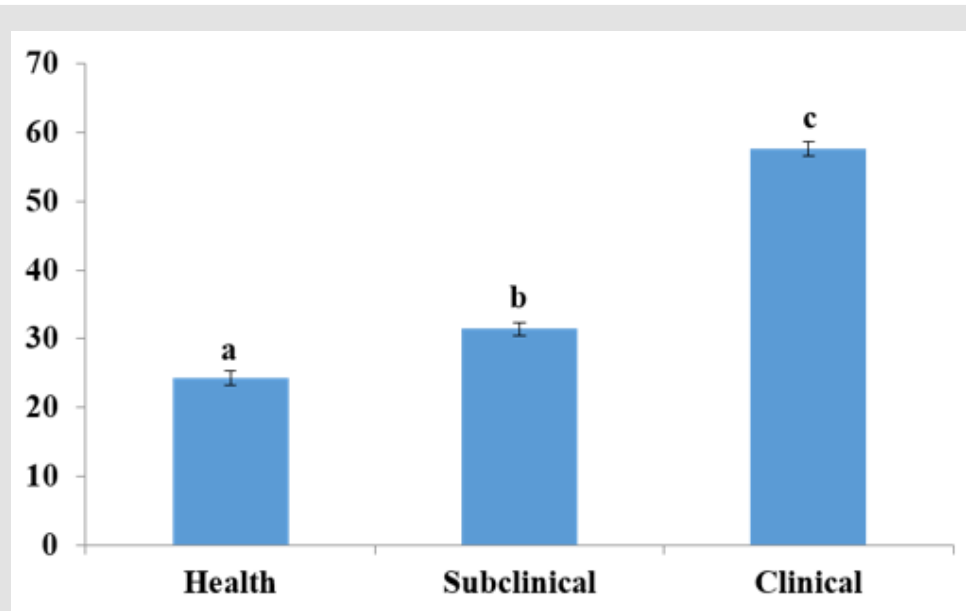

Graph 1: Comparison of milk MDA levels (nM mL-1) from selected groups.

Note: a-cDifferent superscripts indicate that means of MDA differed significantly $(\mathrm{P}<0.05)$. 
In addition, the IMI was positively associated with blood and milk MDA levels as the main cause of lipid peroxidation which is used as an indicator of oxidative stress. Milk with higher SCC has shown to have more infiltrated polymorphonuclear cells, and this caused an increase of oxidative reactions and apoptosis. Lipid peroxidation is a well-established mechanism of oxidative damage caused by reactive oxygen species, and measurement of the MDA provides a convenient index of oxidative stress [3]. In our study the mean level of MDA was significantly higher $(\mathrm{P}<0.05)$ from mastitis milk samples compared with normal milk (Graph 1). In addition, a recent study showed that MDA was a mediator of a decreased milk yield in cows with CM and high SCC [3]. Our results indicate that not only milk from cows with CM but also with SM had higher MDA concentrations as compared to normal milk. Comparison of pathogens causing mastitis in this study showed that MDA levels were different among pathogens causing SM, MDA from quarter milk samples infected with Str. uberis were statistically higher compared to other pathogens (Graph 2).

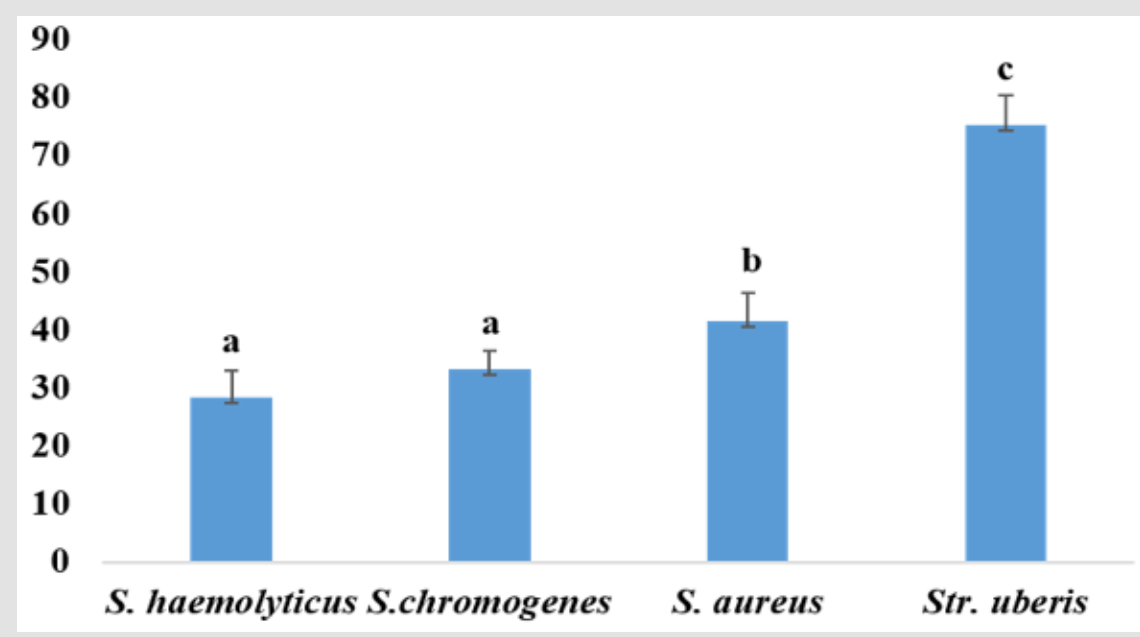

Graph 2: Comparison of milk MDA (nM mL $\left.{ }^{-1}\right)$ levels from selected bacteria causing IMI.

Note: Tukey HSD test; variable MDA approximate probabilities for Post Hoc Tests Error: Between MS $=5.9733, \mathrm{df}=45.000$ a-cDifferent superscripts indicate that means of MDA differed significantly $(\mathrm{P}<0.05)$.

\section{Conclusion}

The results of the current study showed that bacteria such as staphylococci and streptococci were the principal factor causing intramammary infection. It should to keep in mind that polyetiological origin of mastitis in dairy cows means that the effectiveness of generally applicable mastitis control program in the reduction of environmental mastitis bacteria, in combination with the main contagious pathogens of the mammary gland tends to be limited. It is therefore necessary to implement new knowledge for diagnosing mastitis in dairy herds. The measurement of milk MDA level as a significant factor in alterations of the oxidant and antioxidant balance resulting in potent oxidative stress, could be a potential biomarker for diagnosing of mastitis and monitoring health status of udder.

\section{Acknowledgement}

This work was supported by the Slovak projects APVV no. SKPL-18-0088 and VEGA no. 1-0529-19.

\section{References}

1. Pecka Kiełb E, Vasil M, Zachwieja A, Zawadzki W, Elečko J, et al. (2016) An effect of mam-mary gland infection caused by Streptococcus uberis on composition and physicochemical changes of cows' milk. Pol J Vet Sci 19(1): 49-55.

2. Zigo F, Elečko J, Vasil' M, Ondrášovičová S, Farkašová Z, et al. (2019) The occurrence of mastitis and its effect on malondialdehyde level and activity of antioxidant enzymes in dairy cows. Veterinary Medicine Journal 64(10): 423-432.

3. Suriyasathaporn $\mathrm{W}$, Vinitketkumnuen U, Chewonarin T, Boonyayatra S (2006) Higher somatic cell counts resulted in higher malondialdehyde concentrations in raw cows' milk. International Dairy Journal 16(9): 1088-1091.

4. Zigo F, Elečko J, Farkašová Z, Zigová M, Vasil’ M et al. (2019) Preventive methods in reduction of mastits pathogens in dairy cows. Journal of Microbiology, Biotechnology and Food Sciences 9(1): 121-126.

5. Andrei S, Matei S, Rugină D, Bogdan L, Ștefănut C (2016) Interrelationships between the content of oxidative markers, antioxidative status and somatic cell count in cow's milk. Czech. Journal Anim Sci 61: 407-413.

6. Sharma DK, Jallewar PK, Sharm KK (2010) Antibiogram of bacteria isolated from bovine subclinical mastitis. Indian Veterinary Journal 87: 407.

7. Tenhagen BA, Koster G, Wallmann J, Hevwieser W (2006) Prevalence of mastitis pathogens and their resistance against antimicrobial agents in dairy cows in Brandenburg, Germany. Journal of Dairy Science 89(7): $2542-2551$. 
ISSN: 2574-1241

DOI: 10.26717/BJSTR.2019.22.003817

Zigo František. Biomed J Sci \& Tech Res

cC (P) This work is licensed under Creative

Submission Link: https://biomedres.us/submit-manuscript.php

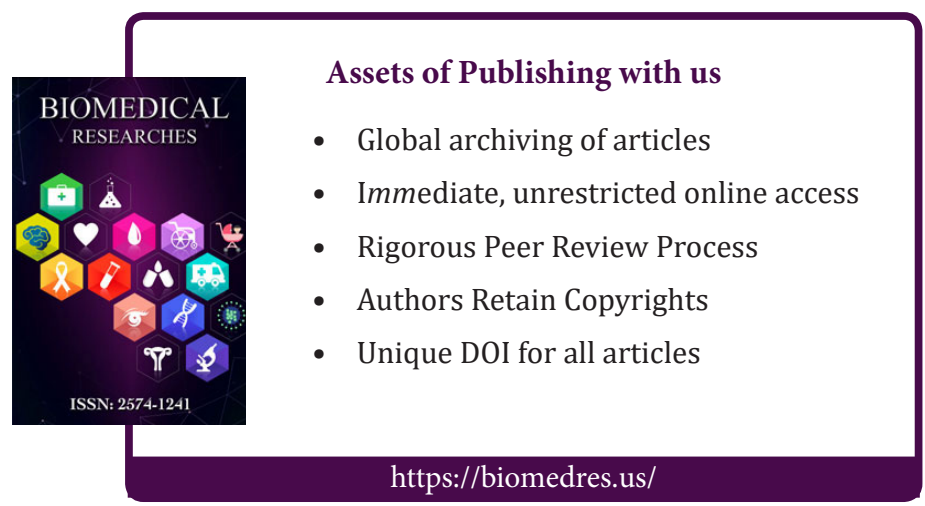

